\title{
Computer application for optimization of turn assignment on a tree-structured irrigation network
}

\author{
A. Almiñana ${ }^{1}$, L. F. Escudero ${ }^{2}$, M. Landete ${ }^{1}$, J. F. Monge ${ }^{1}$, \\ A. Rabasa $^{1} \&$ J. Sánchez-Soriano ${ }^{1}$ \\ ${ }^{1}$ Instituto Centro de Investigación Operativa, \\ Universidad Miguel Hernández, Spain \\ ${ }^{2}$ Departamento de Estadística e Investigación Operativa, \\ Universidad Rey Juan Carlos, Spain
}

\begin{abstract}
Most of the easier structural solutions for greater utilization of water resources have already been implemented. The principal objective of this paper is to develop a methodology for helping to produce irrigation scheduling policies for the deployment of water resources for agricultural use. We have, therefore, developed WISCHE (Water Irrigation Scheduling), a decision support system for irrigation scheduling in an arborescent network. Computational experience has been implemented with satisfactory results in "La Comunidad de Regantes, Riegos de Levante, Canal $2^{\text {nd," }}$, eastern Spain. Its irrigation area covers 2188 Hectares, with 2831 nodes distributed in 20 sectors. Irrigation is needed on a daily basis in five time periods. Network topology, periodical demands and historical consumptions are the inputs and scheduling the hydrants and turns are the output. Assignments must satisfy two types of constraints: the first one based on physical network limitations and the other one based on previous consumptions and demands. In order to deal with the first limitations, a mixed $0-1$ separable quadratic program is proposed. Statistical information about previous consumptions on turns demanded and non-attended demands is used to assign a priority to hydrants. Thus, the system favours hydrants which used what they applied for and hydrants which could not be well attended previously.

Keywords: water resource scheduling, agriculture irrigation, mixed 0-1 separable quadratic programs.
\end{abstract}




\section{Introduction}

Southern Spain is going through a period of serious drought. Due to these circumstances and as a result of the impact of the changes in the general climatic conditions, there is increasing demand on the use of water resources and the need for rational planning and scheduling of water resources is becoming stronger than ever, as is justified by Gomez-Limon and Martinez [1]. We should differentiate between water resource planning (usually long-term) and water distribution scheduling (usually daily basis). In the case of planning, we distinguish between the deterministic environment as proposed by Andreu et al. [2] and the stochastic environment which consider uncertainty among its main parameters such as water inflow and needs as presented by Escudero [3]. We focus on the latter case.

To make an effective use of irrigation water, "La Comunidad General de Regantes, Riegos de Levante, Canal $2^{\text {nd, }}$, in Elche (Spain), is introducing a complete plan for the modernization and improvement of its irrigation infrastructures. A telemetric and monitoring system for the whole irrigation network is being implemented as part of the whole project. Thus, it has become necessary for hydrants to be assigned turns efficiently.

The application we propose generates the turn assignment, by considering physical network constraints and previous usages by farmers.

This paper is organized as follows: the problem definition and the main objective are outlined in section two. The application functionality with a brief description of its modules is presented in the third section. The fourth section offers the results of the computational experiment through a step by step example execution. Finally, in the fifth section some conclusions derived from this software application are presented along with the future research lines to be carried out by the group.

\section{Problem definition and main objective}

The tree-structured irrigation network consists of 2405 hydrants over a surface of 2188 Hectares. There are five four hour turns a day for irrigation. A hydrant can demand one, two, three or four of them, depending on its irrigable surface. Because of network topology constraints and the quantity of water available, some users' demands cannot be attended. So, an assignment generation system becomes necessary.

Thus, our objective is to develop an application for the optimization of turn assignment, which considers both network physical restrictions (flow and pressure) and the priority demand based on previous demand usage in such a way that farmers can be equally attended.

\section{Application functionality}

\subsection{Developing tools}

We chose $\mathrm{C}++$ language for application coding in order to obtain the most efficient program; and the chosen developing tool was Borland Builder ${ }^{\circledR} \mathrm{C}++$ 
v6.0 because of its wide range of facilities in Graphic User Interfaces development. The mathematical optimization model for final assignments was written using CPLEX. The application runs under Microsoft Windows ${ }^{\circledR}$ Operating System.

\subsection{Input data files}

-Network_Topology: This file includes a list of hydrants with their code, coordinates, antecedent node, type and other information. This file is read automatically when application starts and it represents the real tree-structured irrigation network.

-Weekly_Telemetry: This file includes date, hydrant code and daily water consumption in a given week period. These values are provided by the SCADA system and the file is loaded by the user in Telemetria form. If the user wants to a Weekly_Telemetry file is added to the Log_Telemetry file (if it is possible).

-Daily_Applications: This file is generated from a template filled in by the user, and it contains the turn when each hydrant wants to start irrigation. This planning is repeated for every day of the week. This file is loaded by the user in the Solicitudes (Applications) form. Every Daily_Applications file is added to Log_Applications file after processing (if it is possible).

\subsection{Module functionality}

The WISCHE application starts loading the Network Topology file and then the Control Panel brings to users three modules: Telemetrias (Telemetries), Asignación de Prioridades (Priority Assignment), Asignación de Turnos (Turn Assignment). From the Telemetrias module, the user can load the Weekly_Telemetry file and it can be automatically added to the Log_Telemetry file (which was automatically loaded when this form started). This module, optionally, allows the user to show the loaded files, data pre-processing facilities and customizable graphs generation with telemetric data. Customizable graphs generation is described in section 3.3.3.

Asignación de Prioridades (The Priority Allocation) module offers a frame to fill in and change an application form template, the weekly loading application, and the priority generation procedure, described in detail in section 3.3.1. Optionally, the user can show generated priorities and create new customizable graphs with previously applied data.

From Asignación de Turnos (Turn Allocation) module the user defines the previous conditions: maximum speed, minimum pressure, and pressure on headnodes. Optionally, the user can require a maximum speed minimization and/or maximum pressure minimization. Finally the form brings a heuristic use option that generates really good but non-optimal solutions with a very low execution time. It is described in detail in section 3.3.2.

\subsubsection{Priority generation procedure}

The priority associated to a hydrant in a certain turn is calculated as an addition of two factors: the first of which is the previous usage of turns demanded (real 
consumption divided by maximum consumption in a period), and the second factor is the proportion of turns that could not be attended previously. Both of them can be weighed by the user through its impact values. The calculated priorities are returned in a bi-dimensional structure (hydrant, turn). Figure 1 shows the application window used to customize and calculate the priorities.

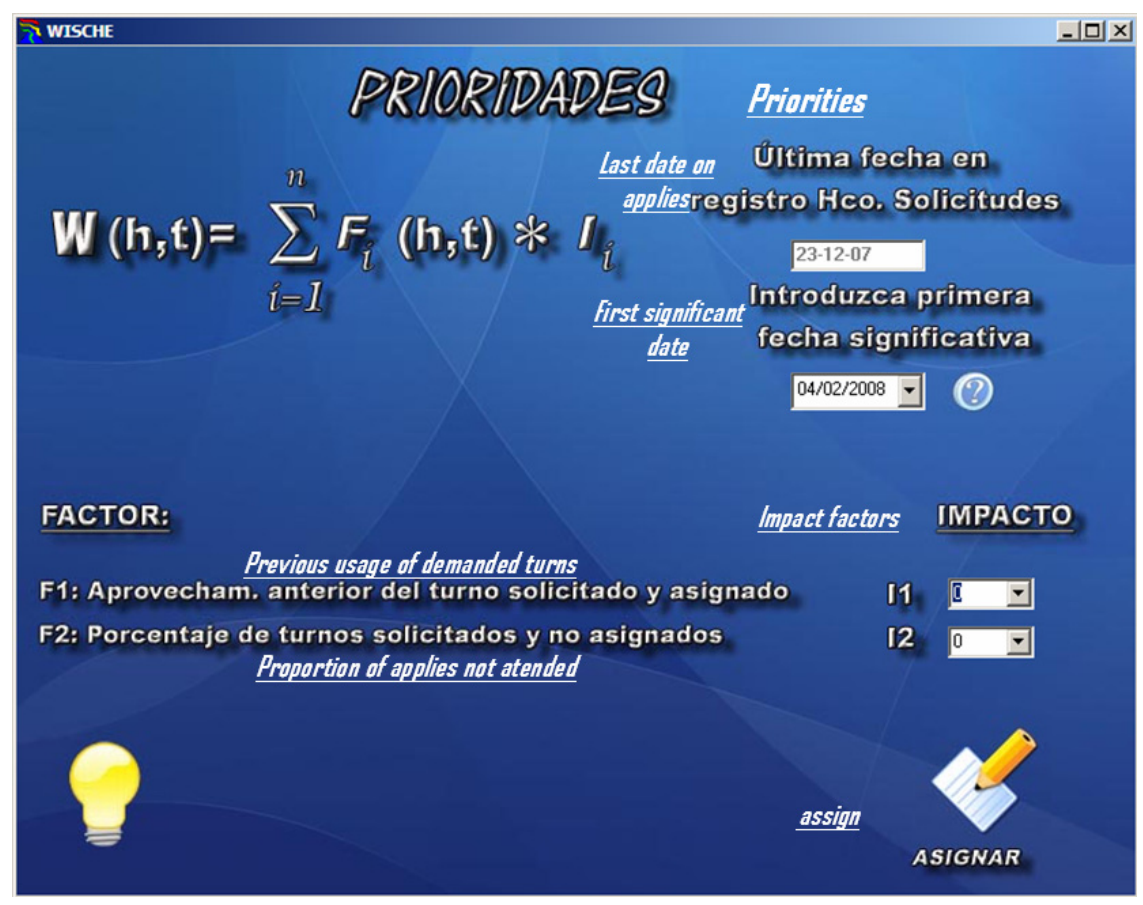

Figure 1: $\quad$ Priorities form.

\subsubsection{Mathematical model for turn assignment}

The objective is to turn on the maximum number of hydrants with the highest priority factor. The pressure head at any hydrant must not fall below the specific threshold. This constraint is formulated by employing the Darcy-Weisbach equation. The discharge of water through each node during each time period is defined too and the water flow velocity allowed along the immediate upstream pipe segment of any node is enforced as shown in Figure 2.

Hydrant irrigation must not be interrupted, in which case it can only be turned on once and will be kept open during consecutive time periods. The irrigation schedule for some hydrants must be fixed, due to logistical considerations imposed by the system operator. All this is considered in the proposed mixed 0-1 program by Almiñana et al. [4]. The computation of the friction factor is calculated by using the Colebrook-White [5] equation. An explicit calculation of the friction factor in a set of special pipes is presented by Yoo et al. [6]. Final turn scheduling is given by iterating this mixed $0-1$ linear problem. Turn assignment results must be filtered as shown in Figure 3. 


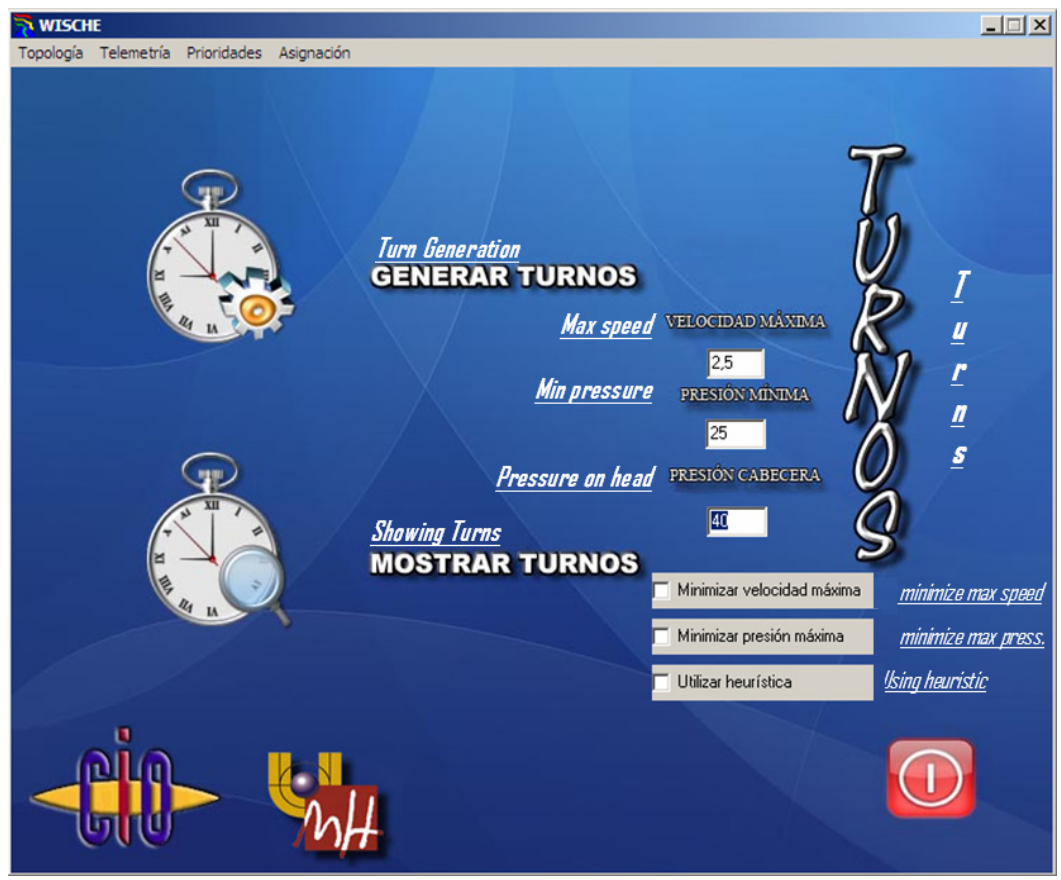

Figure 2: Turn assignment form.

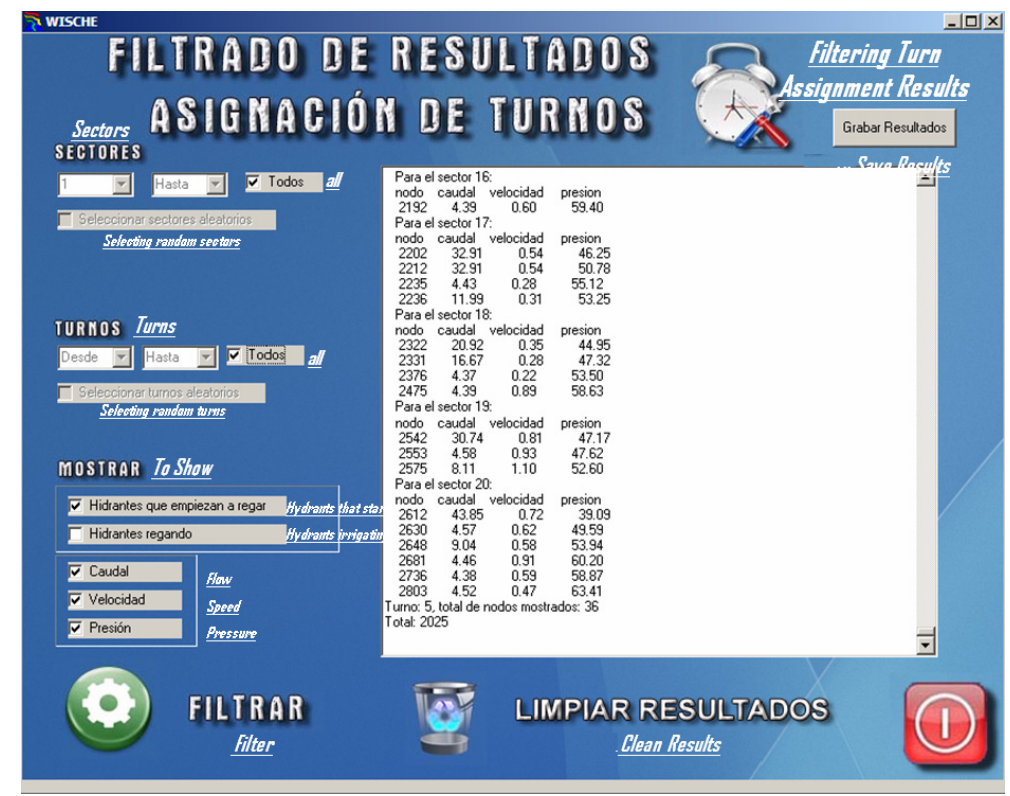

Figure 3: Turn assignment visualization form. 


\subsubsection{Customizable graph generation}

Applications allow the user to create customizable graphs over two data sets: telemetric values and previous applications. The user must select a time period and a type of graph. Also, he can select the parameters he wants to show. There is $3 \mathrm{D}$-visualization and clustering possibilities. Figure 4 shows an example of graph generation with telemetric data where maximum flow is compared.

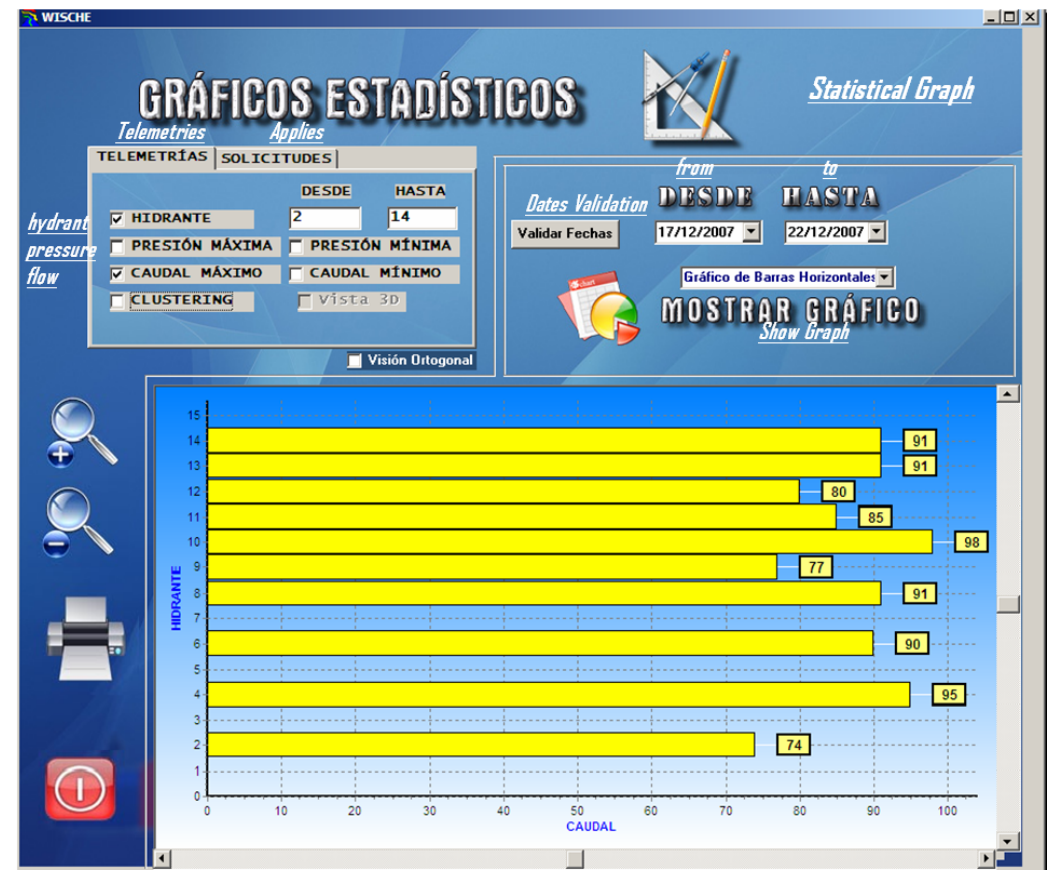

Figure 4: Graph generation form.

\subsection{Output data file.}

-Assignments: This file contains a list of all the hydrants on the network with the turns assigned by the system, for a week. This file is generated by Asignación de Turnos (Turn Allocation) form when the user clicks on this option.

\section{Computational experience}

In this section we show a complete process using WISCHE. The computational experience was executed on an Intel Core Duo 1,66 GHz. Processor, with 2 GB. RAM running under Microsoft Windows ${ }^{\circledR}$ XP Operating System. Topology was a real data file, but the rest of files were simulated because the network infrastructures and the SCADA system had not been completely installed yet. Below, Table 1 shows an example of a complete application trace, where the actions in brackets are optional. 
Table 1: $\quad$ Example of complete application trace.

\begin{tabular}{|c|c|c|c|}
\hline Action & Form & Option & Time /Size \\
\hline Loading topology & Starting & (auto) & $1 \mathrm{sec} . / 321 \mathrm{~Kb}$. \\
\hline Loading telemetric $\log$ file & Telemetries & (auto) & $1 \mathrm{sec} .360 \mathrm{~Kb}$. \\
\hline $\begin{array}{l}\text { Loading weekly telemetries } \\
\text { file }\end{array}$ & Telemetries & $\begin{array}{l}\text { Read Weekly Telem. .or } \\
\text { Record }\end{array}$ & $9 \mathrm{sec} .7360 \mathrm{~Kb}$. \\
\hline [Data pre-processing ] & Telemetries & Data Preprocesing & - \\
\hline [Showing telemetric] & Telemetries & Show Telemetry & - \\
\hline [Graph=generation] & Telemetries & Graphs & - \\
\hline Filling in application form & Pr. Assig. & Application Forms & - \\
\hline Loading weekly applications & Pr. Assig. & $\begin{array}{l}\text { Read weekly Application } \\
\text { Forms }\end{array}$ & $\begin{array}{c}1,5 \mathrm{sec} . / 369 \\
\mathrm{~Kb} .\end{array}$ \\
\hline Priorities generation & Pr. Assig. & Generate Priorities & 4 sec. \\
\hline [Showing priorities] & Pr. Assig. & Show Priorities & - \\
\hline [Graphs generation] & Pr. Assig. & Graphs & - \\
\hline Turns generation & Asig. Tur. & Generate Turns & $2,5-12$ min. \\
\hline [Showing turns] & Asig. Tur. & Show Turns & - \\
\hline
\end{tabular}

\section{Conclusions}

WISCHE is an application built in collaboration with Riegos de Levante, an irrigation community which has a real need for irrigation scheduling because water demands usually exceed water availability. This software allows irrigation community managers to schedule hydrant turns one week in advance. Scheduling is as flexible as possible and the priority system presented allows for all farmers to be attended according to their previous usages, so farmers who make early applications and usually make reasonable use of their demands are benefited.

Because all types of problem restrictions are considered, the turn assignment model brings optimal solutions in a really short time $(12 \mathrm{~min})$. If heuristics are used, this time is reduced to 2 or $3 \mathrm{~min}$. and turn scheduling is produced, which managers consider as quite good and network operation is safe even in critical conditions of water demand.

Also, by using the WISCHE graphic facilities, the farmers' behaviour becomes more understandable, and network telemetric log files can be examined in detail highlighting flow and pressure conditions in the most demanded turns.

At present, the authors are researching new heuristics to reduce the application running time, and therefore obtain satisfactory scheduling. Also, Data Mining techniques, such as Classification Rules, are being studied to be incorporated in a new predictive module.

\section{References}

[1] Gomez-Limon, J.A., Martinez, Y. Multi-criteria modelling of irrigation water market at basin level: A Spanish case study. European Journal of Operational Research, 173, pp. 313-336, 2006.

[2] Andreu, J., Capilla, J., Sanchos, E. AQUATOOL, a generalizad decisiónsupport system for water-resources planning and operational management. Journal of Hydrology, 177, pp. 269-291, 1996. 
262 Sustainable Irrigation Management, Technologies and Policies II

[3] Escudero, L.F., WARSYP, a robust approach for water resources planning under uncertainty. Annals of Operations Research, 95, pp. 313-339, 2000.

[4] Almiñana, M., Escudero, L.F., Landete, M., Monge, J.F., Rabasa, A., Sanchez-Soriano, J., On a mixed 0-1 separable quadratic program for water irrigation scheduling, IIE Transactions, 40:4, pp. 398-405, 2008

[5] Colebrook, C.F., Turbulent flow in pipes, with particular reference to the transition region between the smooth and rough pipe laws. Journal of the Institute of Civil Engineers, 11, pp. 133-156, 1938

[6] Yoo, D.H., Singh, V.P., Explicit design of commercial pipes with no secondary losses. Journal of Irrigation and Drainage Engineering, 130, pp. 437-440, 2004. 